\title{
Competitiveness Evaluation of High-Quality Manufacturing Development in the Yangtze River Economic Belt
}

\author{
Quan Zhang ${ }^{1}$, Renyan $\mathrm{Mu}^{1}$, Zhen Zhang ${ }^{2 *}$, Yue $\mathrm{Hu}^{3}$, Chunjiao Liu ${ }^{1}$, Lu Zhang ${ }^{1}$, Xiao Yu ${ }^{1}$ \\ ${ }^{1}$ School of Management, Wuhan University of Technology, Wuhan 430070, China \\ ${ }^{2}$ School of Economics, Shenzhen Polytechnic, Shenzhen 518055, China \\ ${ }^{3}$ State Street Corporation, 200 Newport Avenue Extension, Quincy, MA 02171, The United States
}

Corresponding Author Email: cherryzhangzhen@szpt.edu.cn

https://doi.org/10.18280/ijsdp.150611

Received: 28 February 2020

Accepted: 19 June 2020

\section{Keywords:}

high-quality manufacturing development (HQMD), competitiveness evaluation, Yangtze River Economic Belt (YREB), improved entropy technique for order preference by similarity to ideal solution (TOPSIS) model

\begin{abstract}
This paper aims to construct the evaluation index system and model for the competitiveness of high-quality manufacturing development in China, and put forward pertinent suggestions. To this end, the evaluation index system was designed in reference to the input-process-output model of the systems theory; the entropy method was improved through analytic hierarchy process (AHP), and then combined with the technique for order preference by similarity to ideal solution (TOPSIS) into the improved entropy TOPSIS model. On this basis, the competitiveness of the Yangtze River Economic Belt (YREB) in high-quality manufacturing development (HQMD) was evaluated with the panel data of 2013-2018, in terms of overall competitiveness, spatial and temporal trends, industrial landscape, and national ranking. The results show that: The overall HQMD competitiveness improved steadily, under the strong boost from two factors and slight constraint from two factors. In terms of space, the HQMD competitiveness was stronger in the east, with widening regional gaps; in terms of time, the HQMD competitiveness was improving across the board, especially in the central region. Five provinces maintain steady growth of HQMD competitiveness, and six provinces witnessed fluctuating growth. In the final manufacturing landscape, there were one leader, two subleaders, three supporters, and five followers. The YREB is the demonstration zone of China's HQMD, with $80 \%$ of its provinces falling in medium and high levels. Finally, several suggestions were presented to improve the HQMD competitiveness in the YREB. The research findings provide a good reference for policymakers to promote manufacturing and pursue sustainable development.
\end{abstract}

\section{INTRODUCTION}

High-quality development (HQD) is synonymous with sustainable development in many respects. For China's manufacturing industry, HQD is the only path towards sustainable development. Facing immense pressures from within and without, Chinese manufacturers must complete the paradigm shift from fast growth to HQD, trying to acquire and maintain a competitive edge in the new round of global competition centered on intelligent manufacturing.

However, HQD is a relatively new concept. There is not yet a clear and unified definition of high-quality manufacturing development (HQMD), not to mention scientific evaluation indices. As a result, it is very difficult to evaluate the competitiveness or formulate industrial policies of HQMD. To effectively promote HQMD in China, the most urgent task is to establish a scientific evaluation index system and carry out accurate competitiveness evaluation.

Both HQD and HQMD are concepts with strong Chinese features. At present, foreign studies on HQD mainly focus on its core contents, such as technical innovation, green manufacturing, and structural upgrading. Some scholars highlighted the importance of technical innovation, and treated innovation indices as the core metrics of HQD [1-3]. Some characterized HQD as efficient resource allocation, and industrial transformation and upgrading [4-6]. Some pointed out the three key aspects of HQD: coordination between industrial growth and environment, green manufacturing, and green sustainable development [7-10].

In China, scholars mainly investigated the evaluation indices of HQMD, and put forward core indices like innovation, greenness, opening, structure, benefit, efficiency, quality, and integration [11-13]. Their findings provide useful references for the design of HQMD indices. However, the existing research has three common defects: the evaluation index system lacks a scientific basis, that is, clear understanding of HQMD; the current evaluation models are too theoretical to be directly applied; the policy suggestions are not very pertinent, due to the lack of empirical research on HQMD competitiveness.

In this background, this paper attempts to achieve the following objectives: First, clarify the connotation of HQMD based on the input-process-output model of the systems theory, and construct a scientific evaluation index for HQMD competitiveness; Second, improve the entropy method by analytic hierarchy process (AHP), and then create a novel evaluation model for HQMD competitiveness, called improved entropy technique for order preference by similarity 
to ideal solution (TOPSIS) model; Third, evaluate HQMD competitiveness empirically based on the panel data in the Yangtze River Economic Belt (YREB), and put forward some pertinent suggestions.

The remainder of this paper is organized as follows: Section 2 explains the connotation of HQMD, and set up an evaluation index system; Section 3 constructs the improved TOPSIS model; Section 4 empirically evaluates HQMD competitiveness in the YREB; Section 5 puts forward the conclusions and suggestions.

\section{CONNOTATION OF HQMD AND EVALUATION INDEX SYSTEM}

\subsection{Connotation of HQMD}

Before clarifying the connation of HQMD, it is necessary to understand some relevant concepts, namely, quality, product quality, quality of industrial development, quality of manufacturing development and HQD. In economics, quality is a value judgement about the level or degree of an object; product quality measures the value of a product by how much it meets social needs [14]. The quality of industrial development is the overall quality of various products, covering a static dimension (quantity of products/services) and a dynamic dimension (evolution of industrial structure). The quality of manufacturing development is the extension of the quality of industrial development in the manufacturing field.
HQD is an advanced state of development, which is high-end, efficient, fair, green, and sustainable. HQD could be achieved through benefit improvement, innovation, structural optimization, intensive development, and comprehensive coordination [15]. Finally, HQMD is the extension of HQD in the manufacturing field.

Based on the above concepts, this paper defines HQMD as an advanced development mode of manufacturing with a certain scale, in which multiple outputs, namely, structural upgrading, benefit optimization, environmental coordination, and opening \& freedom, are optimized by increasing the input of innovation elements and improving resource allocation. HQMD is the advanced state of the quality of manufacturing development, providing the material products that satisfy people's need for a better life. This definition emphasizes on the following aspects of HQMD: the innovation elements in the input system, intensive utilization in the process system, and economic benefits, environmental protection and opening in the output system.

\subsection{Evaluation index system}

According to the connotation of HQMD, this paper sets up an evaluation index system of HQMD competitiveness from six perspectives: innovation, intensive utilization, structural upgrading, benefit optimization, environmental coordination, and opening $\&$ freedom. The entire evaluation index system is displayed in Table 1 .

Table 1. Evaluation index system for HQMD competitiveness

\begin{tabular}{|c|c|c|c|}
\hline Primary index & Secondary index & Tertiary index & Calculation formula \\
\hline \multirow{4}{*}{$\begin{array}{l}\text { Innovation } \\
\text { (A) }\end{array}$} & Innovation inputs (A1) & $\begin{array}{l}\text { Proportion of R\&D talents } \\
\text { (A11) } \\
\text { Proportion of R\&D } \\
\text { expenditure (A12) }\end{array}$ & $\begin{array}{c}\text { Number of manufacturing R\&D employees / annual } \\
\text { mean number of manufacturing employees } \\
\text { Manufacturing R\&D expenditure / gross domestic } \\
\text { product (GDP) }\end{array}$ \\
\hline & \multirow{3}{*}{ Innovation outputs (A2) } & Proportion of patents (A21) & Number of patents / number of patent applications \\
\hline & & $\begin{array}{l}\text { Per-capita number of } \\
\text { invention patents (A22) }\end{array}$ & $\begin{array}{c}\text { Number of patents / mean number of } \\
\text { manufacturing employees }\end{array}$ \\
\hline & & $\begin{array}{l}\text { Proportion of new products } \\
\text { (A23) }\end{array}$ & $\begin{array}{l}\text { Main business income of new manufacturing } \\
\text { products / main business income of manufacturing }\end{array}$ \\
\hline \multirow{4}{*}{$\begin{array}{l}\text { Intensive } \\
\text { utilization } \\
\text { (B) }\end{array}$} & Capital allocation efficiency (B1) & Capital productivity (B11) & $\begin{array}{l}\text { Manufacturing added value / total investment in } \\
\text { manufacturing fixed assets }\end{array}$ \\
\hline & Labor allocation efficiency (B2) & Labor productivity (B21) & $\begin{array}{c}\text { Manufacturing added value / annual mean number } \\
\text { of employees }\end{array}$ \\
\hline & Energy allocation efficiency (B3) & Energy productivity (B31) & $\begin{array}{c}\text { Manufacturing added value / total manufacturing } \\
\text { energy consumption }\end{array}$ \\
\hline & Land allocation efficiency (B4) & Land productivity (B41) & Manufacturing added value / urban built-up area \\
\hline \multirow{5}{*}{$\begin{array}{l}\text { Structural } \\
\text { upgrading } \\
\text { (C) }\end{array}$} & Product structural upgrading $(\mathrm{C} 1)$ & Qualified product rate $(\mathrm{C} 11)$ & $\begin{array}{c}\text { Batch of qualified products / batch of spot check } \\
\text { products }\end{array}$ \\
\hline & \multirow{3}{*}{$\begin{array}{l}\text { Enterprise structural upgrading } \\
\qquad(\mathrm{C} 2)\end{array}$} & $\begin{array}{l}\text { Superior product rate }(\mathrm{C} 12) \\
\text { Proportion of high-tech } \\
\text { enterprises }(\mathrm{C} 21)\end{array}$ & $\begin{array}{c}\text { Superior product rate in statistical yearbooks } \\
\text { Number of high-tech enterprises / numbers of } \\
\text { manufacturing enterprises }\end{array}$ \\
\hline & & $\begin{array}{l}\text { Proportion of R\&D } \\
\text { enterprises (C22) }\end{array}$ & $\begin{array}{l}\text { Number of enterprises with R\&D activities / } \\
\text { number of manufacturing enterprises }\end{array}$ \\
\hline & & $\begin{array}{l}\text { Proportion of top-500 } \\
\text { enterprises (C23) }\end{array}$ & $\begin{array}{l}\text { Number of to- } 500 \text { manufacturing enterprises / } \\
\text { number of manufacturing enterprises }\end{array}$ \\
\hline & dustry structural upgrading $(\mathrm{C} 3)$ & $\begin{array}{l}\text { Proportion of high-tech } \\
\text { manufacturing }(\mathrm{C} 31)\end{array}$ & $\begin{array}{l}\text { Main business income of high-tech manufacturing / } \\
\text { main business income of manufacturing }\end{array}$ \\
\hline \multirow{4}{*}{$\begin{array}{l}\text { Benefit } \\
\text { optimization } \\
\text { (D) }\end{array}$} & \multirow{2}{*}{$\begin{array}{l}\text { Economic benefit optimization } \\
\text { (D1) }\end{array}$} & Profit margin (D11) & $\begin{array}{c}\text { Total manufacturing profit / main business income } \\
\text { of manufacturing }\end{array}$ \\
\hline & & Output contribution (D12) & Manufacturing added value / GDP \\
\hline & Social benefit optimization (D2) & $\begin{array}{l}\text { Tax contribution (D21) } \\
\text { Employment contribution } \\
\text { (D22) }\end{array}$ & $\begin{array}{l}\text { Manufacturing tax / total tax } \\
\text { Annual mean number of manufacturing employees } \\
\text { / total number of employees }\end{array}$ \\
\hline & $\begin{array}{c}\text { Ecological } \\
\text { benefit optimization (D3) }\end{array}$ & Green cycle rate (D31) & $\begin{array}{l}\text { Comprehensive utilization rate of manufacturing } \\
\text { solid waste in statistical yearbooks }\end{array}$ \\
\hline
\end{tabular}




\begin{tabular}{|c|c|c|c|}
\hline & Wastewater emission (E1) & $\begin{array}{l}\text { Wastewater emission per unit } \\
\text { added value (E11) }\end{array}$ & $\begin{array}{l}\text { Manufacturing wastewater emission / } \\
\text { manufacturing added value }\end{array}$ \\
\hline $\begin{array}{l}\text { Environment } \\
\text { coordination }(\mathrm{E})\end{array}$ & Exhaust gas emission (E2) & $\begin{array}{c}\text { Exhaust gas emission per unit } \\
\text { added value (E21) }\end{array}$ & $\begin{array}{l}\text { Manufacturing sulfur dioxide emission / } \\
\text { manufacturing added value }\end{array}$ \\
\hline \multirow{3}{*}{$\begin{array}{l}\text { Opening \& } \\
\text { freedom } \\
\text { (F) }\end{array}$} & Solid waste emission (E3) & $\begin{array}{l}\text { Solid waste emission per unit } \\
\text { added value (E31) }\end{array}$ & $\begin{array}{l}\text { Manufacturing solid waste emissions / } \\
\text { manufacturing added value }\end{array}$ \\
\hline & Freedom of foreign trade (F1) & $\begin{array}{l}\text { Foreign trade dependence } \\
\qquad(\mathrm{F} 11)\end{array}$ & $\begin{array}{c}\text { Total manufacturing import and export / total } \\
\text { manufacturing output }\end{array}$ \\
\hline & $\begin{array}{l}\text { Freedom of foreign investment } \\
\qquad(\mathrm{F} 2)\end{array}$ & $\begin{array}{l}\text { Foreign capital dependence } \\
\qquad(\mathrm{F} 21)\end{array}$ & $\begin{array}{l}\text { Total assets of foreign enterprises / total } \\
\text { manufacturing assets }\end{array}$ \\
\hline
\end{tabular}

Among them, innovation is the primary driver of HQMD. Innovation requires inputs like talents and expenditure of research and development (R\&D) [16], and outputs patents and new products [17].

Intensive utilization is the key for manufacturing to realize sustainable development under tight resource constraints. It is mainly reflected by the allocation efficiencies of manufacturing inputs, such as capital, labor, energy and land [18].

Hence, the primary index of intensive utilization was decomposed to the allocation efficiencies of capital, labor, energy and land, which can be measured by productivity.

Structural upgrading is the goal of HQMD in terms of industrial structure. Since the industrial structure is a hierarchy of product structure, enterprise structure and industry structure [19], the primary index of structural upgrading was split into the structural upgrading of product, enterprise, and industry.

Benefit optimization is the benefit goal of HQMD. The development of manufacturing generally brings three kinds of benefits: economic benefit, social benefit, and ecological benefit [20]. Hence, the primary index of benefit optimization was divided into economic benefit optimization, social benefit optimization, and ecological benefit optimization. Specifically, the optimization of economic benefit was measured by the contribution to manufacturing profit and added value, that of social benefit was measured by the contribution to tax and employment, and that of ecological benefit was measured by pollution control.

Environmental coordination, as the environmental goal of HQMD, aims to lower the emissions of wastewater, exhaust gas, and solid waste [21]. The emission of each pollutant was measured per unit of manufacturing added value.

Opening \& freedom the desired degree of opening for HQMD, reflecting the integration of manufacturing in the global industrial chain. This primary index was decomposed into foreign trade freedom and foreign investment freedom [22], measured by foreign trade dependence and foreign capital dependence, respectively.

In total, our evaluation index system contains 6 primary indices, 17 secondary indices, and 25 tertiary indices. Only 3 of these indices, namely, wastewater emission, exhaust gas emission, and solid waste emission, are negative. The other indices all have positive correlations with HQMD competitiveness.

\section{IMPROVED ENTROPY TOPSIS MODEL}

\subsection{Selection and improvement of evaluation model}

In economics and management, competitiveness is commonly evaluated by fuzzy evaluation, delph approach, AHP, entropy method, and TOPSIS. Each of these methods has its strengths and weaknesses.

Fuzzy evaluation mainly deals with qualitative problems that cannot be accurately depicted by data. Delphi approach relies too much on the subjective scores rated by experts. AHP has difficulty in passing the consistency test, in the presence of too many indices. Entropy method and TOPSIS are more suitable than the above methods for our research.

Entropy method is a relatively objective weighting method. Each index is weighted based on its degree of variation. If the index value is highly dispersed, the weight assigned to the index might be inaccurate.

To overcome this defect, entropy method is often combined with TOPSIS for scientific research. TOPSIS provides a solution to multi-objective decision-making. Through TOPSIS, the competitiveness of the evaluation object is measured by its distance to the best or worst scheme. Drawing on the relevant literature, this paper improves the entropy method by the AHP, and then combines the improved entropy method with TOPSIS to evaluate the HQMD competitiveness.

\subsection{Steps of model construction}

The improved entropy TOPSIS model was constructed in the following steps:

Step 1. Data normalization

Let $y_{i j t}$ be the value of index $\mathrm{j}$ of province $\mathrm{i}$ in year $\mathrm{t} ; y_{j}^{\max }$ and $y_{j}^{\text {min }}$ be the maximum and minimum values of index $j$, respectively; $x_{i j t} \in[0.1,1]$ is the normalized value. Then, $y_{i j t}$ can be normalized as follows:

If index $\mathrm{j}$ is a positive index:

$$
x_{i j t}=\left(\frac{y_{i j t}-y_{j}^{\min }}{y_{j}^{\text {max }}-y_{j}^{\text {min }}}\right) * 0.9+0.1
$$

If index $\mathrm{j}$ is a negative index:

$$
x_{i j t}=\left(\frac{y_{j}^{\max }-y_{i j t}}{y_{j}^{\max }-y_{j}^{\min }}\right) \times 0.9+0.1
$$

Step 2. Entropy calculation

The entropy of each index was calculated by the global entropy method. The $\mathrm{n}$ indices of province $\mathrm{m}$ in year $t$ were arranged chronologically, forming a global judgment matrix $m t \times n$. Then, the entropy $e_{j}$ of index $\mathrm{j}$ can be calculated by:

$$
e_{j}=-\frac{1}{\ln (m T)} \sum_{i=1}^{m} \sum_{t=1}^{T}\left(f_{i j t} * \ln f_{i j t}\right)
$$

The $f_{i j t}$ can be obtained by:

$$
f_{i j t}=\frac{x_{i j t}}{\sum_{i=1}^{m} \sum_{t=1}^{T} x_{i j t}}
$$


Step 3. AHP-based improvement

(1) The difference coefficient $g_{j}$, maximum difference coefficient $D$, and mapping ratio $R$ of index $j$ can be respectively calculated by:

$$
\begin{aligned}
g_{j} & =1-e_{j} \\
D & =\frac{\operatorname{maxg}_{j}}{\operatorname{ming}_{j}} \\
R & =\sqrt[\partial-1]{\frac{D}{\partial}}
\end{aligned}
$$

where, $\partial$ is the adjustment coefficient. If $D \leq 9, \partial$ is the integer closest to $D$; otherwise, $\partial$ equals 9 . The first power of $(\partial-1)$ is to distribute $D$ evenly on the mapping values of the 1-9 scale. Here, $D / \partial$ is adopted to make the mapping values of the 1-9 scale consistent with the mapping structure of the AHP.

(2) The mapping values of the 1-9 scale were obtained, and multiplied with $R^{\mathrm{n}-1}$ to get the mapping values of the improved entropy method (Table 2).

(3) To construct the judgment matrix $R$, the difference coefficient ratio between every two indices was calculated by:

$$
r_{j k}=\frac{g_{j}}{g_{k}}
$$

If $r<1$ :

$$
r_{k j}=\frac{g_{k}}{g_{j}}
$$

The minimum difference between $R$ and mapping value was taken as the relative importance of the two indices. Then, the judgment matrix of the improved entropy method was constructed based on the relative importance.
(4) The weight $w_{j}$ of each index was calculated through the AHP, according to the judgement matrix.

Step 4. TOPSIS model construction

(1) The weighting matrix B can be created by:

$$
\begin{gathered}
B=\left(b_{i j t}\right) m T \times n \\
b_{i j t}=w_{j} \times x_{i j t}
\end{gathered}
$$

(2) The best scheme $Q_{j}^{+}$and worst scheme $Q_{j}^{-}$can be respectively calculated by:

$$
\begin{array}{r}
Q_{j}^{+}=\left(\max _{i 1 t}, \max b_{i 2 t}, \ldots, \max b_{i n t}\right) \\
Q_{j}^{-}=\left(\min b_{i 1 t}, \min b_{i 2 t}, \ldots, \min b_{i n t}\right)
\end{array}
$$

(3) The Euclidean distances $d_{i}^{+}$and $d_{i}^{-}$from each index to the optimal and worst schemes can be respectively obtained by:

$$
\begin{aligned}
& d_{i}^{+}=\sqrt{\sum_{j=1}^{m}\left(Q_{j}^{+}-b_{i j t}\right)^{2}} \\
& d_{i}^{-}=\sqrt{\sum_{j=1}^{m}\left(Q_{j}^{-}-b_{i j t}\right)^{2}}
\end{aligned}
$$

(4) The proximity between each index and the ideal scheme can be calculated by:

$$
C_{i}=\frac{d_{i}^{-}}{d_{i}^{+}+d_{i}^{-}}
$$

where, $C_{i}$ falls between 0 and 1 . The closer the $C_{i}$ value is to 1 , the better is the result.

Table 2. The mapping values of the 1-9 scale

\begin{tabular}{cccccccccc}
\hline Level & 1 & 2 & 3 & 4 & 5 & 6 & 7 & 8 & 9 \\
\hline Mapping value & $1 \times R^{0}$ & $2 \times R^{1}$ & $3 \times R^{2}$ & $4 \times R^{3}$ & $5 \times R^{4}$ & $6 \times R^{5}$ & $7 \times R^{6}$ & $8 \times R^{7}$ & $9 \times R^{8}$ \\
\hline
\end{tabular}

\section{EMPIRICAL ANALYSIS}

\subsection{Sample selection}

The YREB was selected as the study area, for its representativeness of China's manufacturing development. As one of the three major economic regions in China, the YREB spans across 11 provincial administrative regions (hereinafter referred to as provinces) in eastern, central, and western China. The study area takes up over $40 \%$ of China's population and GDP. In addition, there are important manufacturing bases across the YREB, whether in the upper, middle, or lower reaches. The HQMD of the YREB not only bears on the overall HQMD of China, but also determines the strategic positioning of the YREB.

\subsection{Data sources}

For the consistency and completeness of various indices, the relevant data were selected from statistical yearbooks published in the sample period of 2013-2018, and downloaded from official websites of relevant authorities. Specifically, the data on R\&D and patents are from China Statistical Yearbooks on Science and Technology, the data on high-tech enterprises are from China Statistics Yearbooks on High Technology Industry, the data on manufacturing enterprises above designated size are from the China Industry Statistical Yearbooks, the data on fixed asset investment are from the Statistical Yearbook of the Chinese Investment in Fixed Assets, the data on import and export are from the foreign trade database of the Development Research Center of the State Council, the tax data are from the Ministry of Finance and State Administration of Taxation, the data on top-500 enterprises are from the List of Top 500 Manufacturing Enterprises in China, and the data on GDP, environment, and other issues are from China Statistical Yearbooks and provincial statistical yearbooks.

\subsection{Index weighting}

The weight of each index was calculated by the improved entropy method. As shown in Table 3, all consistency ratios 
(CRs) were smaller than 0.1 , passing the consistency test. The weights reflect the relative importance of each index. The highest weight belongs to structural upgrading, indicating that structural upgrading has a great impact on China's manufacturing in recent years. The second highest weight belongs to innovation, which proves the driving effect of innovation on HQMD. The lowest weight belongs to environment coordination. Thus, it is an urgent task for China to mitigate the environmental impact of manufacturing development.

Table 3. The weights of evaluation indices

\begin{tabular}{|c|c|c|c|c|c|c|c|}
\hline Primary index & Weight & CR & Secondary index & Weight & $\mathbf{C R}_{\mathbf{i}}$ & Tertiary index & Weight \\
\hline \multirow{5}{*}{ Innovation (A) } & \multirow{5}{*}{0.2592} & & \multirow{2}{*}{ A1 } & \multirow{2}{*}{0.1225} & \multirow{5}{*}{0.0079} & A11 & 0.0601 \\
\hline & & & & & & A12 & 0.0624 \\
\hline & & & \multirow{3}{*}{ A2 } & \multirow{3}{*}{0.1367} & & A21 & 0.0276 \\
\hline & & & & & & A22 & 0.0601 \\
\hline & & & & & & A23 & 0.0491 \\
\hline \multirow{4}{*}{ Intensive utilization (B) } & \multirow{4}{*}{0.1588} & & B1 & 0.0613 & \multirow{4}{*}{0.0012} & B11 & 0.0613 \\
\hline & & & B2 & 0.0341 & & B21 & 0.0341 \\
\hline & & & B3 & 0.0294 & & B31 & 0.0294 \\
\hline & & & B4 & 0.0341 & & B41 & 0.0341 \\
\hline \multirow{6}{*}{ Structural upgrading $(\mathrm{C})$} & \multirow{6}{*}{0.2757} & & \multirow[b]{2}{*}{$\mathrm{C} 1$} & \multirow{2}{*}{0.0467} & \multirow{6}{*}{0.0245} & C11 & 0.0173 \\
\hline & & & & & & $\mathrm{C} 12$ & 0.0294 \\
\hline & & & & & & $\mathrm{C} 21$ & 0.0499 \\
\hline & & 0.0134 & $\mathrm{C} 2$ & 0.1693 & & $\mathrm{C} 22$ & 0.0597 \\
\hline & & & & & & $\mathrm{C} 23$ & 0.0597 \\
\hline & & & $\mathrm{C} 3$ & 0.0597 & & C31 & 0.0597 \\
\hline \multirow{5}{*}{ Benefit optimization (D) } & \multirow{5}{*}{0.1293} & & \multirow{2}{*}{ D1 } & \multirow{2}{*}{0.0323} & \multirow{5}{*}{0.0044} & D11 & 0.0142 \\
\hline & & & & & & D12 & 0.0181 \\
\hline & & & D2 & 00629 & & D21 & 0.0299 \\
\hline & & & & 0.0629 & & D22 & 0.0330 \\
\hline & & & D3 & 0.0341 & & D31 & 0.0341 \\
\hline \multirow{3}{*}{ Environment coordination (E) } & \multirow{3}{*}{0.0314} & & E1 & 0.0126 & \multirow{3}{*}{0} & E11 & 0.0126 \\
\hline & & & E2 & 0.0097 & & $\mathrm{E} 21$ & 0.0097 \\
\hline & & & E3 & 0.0091 & & E31 & 0.0091 \\
\hline \multirow{2}{*}{ Opening \& freedom $(\mathrm{F})$} & \multirow{2}{*}{0.1456} & & $\mathrm{~F} 1$ & 0.0750 & \multirow{2}{*}{0} & F11 & 0.0750 \\
\hline & & & $\mathrm{F} 2$ & 0.0706 & & $\mathrm{~F} 21$ & 0.0706 \\
\hline
\end{tabular}

\subsection{Results analysis}

Tables 4-8 present the evaluation results on HQMD competitiveness of the YREB in 2013-2018. From different perspectives, the evaluation results were analyzed in details below.

(1) The overall HQMD competitiveness improved steadily, under the strong boost from two factors and slight constraint from two factors.

Table 4 provides the overall HQMD competitiveness of the YREB in 2013-2018. It can be seen that HQMD competitiveness of the YREB increased by $16.46 \%$ from 0.2917 to 0.3397 in the sample period.

To be specific, innovation and structural upgrading, as main drivers of HQMD, both grew substantially by over $42 \%$. Environment coordination and intensive utilization, as important propellers of HQMD, increased by $22.68 \%$ and $15.64 \%$, respectively. On the contrary, benefit optimization and opening \& freedom, which restrict HQMD, plunged by $18.57 \%$ and $15.20 \%$, respectively.
Overall, the HQMD competitiveness of the YREB increased substantially in the sample period: the innovation was significantly enhanced, the industrial structure was greatly optimized, the resource allocation was made much more efficient, and the environment was better coordinated; however, benefit optimization and opening \& freedom became to major obstacles of HQMD.

The decline of benefit optimization is directly attributed to the dwindling contributions of manufacturing to GDP ($6.98 \%)$, tax (-6.56\%), and employment (-7.59\%). The dwindling is inevitable as the YREB undergoes the transform from real economy to fictitious economy. The dominance of manufacturing is being replaced by service industry, finance, and real estate, weakening the benefit contribution of manufacturing. The decline of opening \& freedom comes from the diminishing freedom of foreign trade $(-0.25 \%)$ and foreign investment $(-0.02 \%)$. In recent years, China's manufacturing has become less attractive in the international market, as developed countries are promoting the return of high-end manufacturing, and other developing countries are gnawing away the shares in low- and mid-end markets.

Table 4. The overall HQMD competitiveness of the YREB in 2013-2018

\begin{tabular}{cccccccc}
\hline Year & HQMD competitiveness & $(\mathbf{A})$ & $(\mathbf{B})$ & $(\mathbf{C})$ & (D) & (E) & (F) \\
\hline 2013 & 0.2917 & 0.2151 & 0.2673 & 0.2712 & 0.5623 & 0.6935 & 0.2704 \\
2014 & 0.2994 & 0.2279 & 0.2752 & 0.2958 & 0.5550 & 0.7393 & 0.2572 \\
2015 & 0.3056 & 0.2414 & 0.2865 & 0.3065 & 0.5331 & 0.7722 & 0.2535 \\
2016 & 0.3165 & 0.2635 & 0.2907 & 0.3274 & 0.5224 & 0.7910 & 0.2500 \\
2017 & 0.3262 & 0.2828 & 0.2938 & 0.3553 & 0.5049 & 0.7910 & 0.2337 \\
2018 & 0.3397 & 0.3057 & 0.3091 & 0.3860 & 0.4579 & 0.8508 & 0.2293 \\
Cumulative growth & $16.46 \%$ & $42.12 \%$ & $15.64 \%$ & $42.33 \%$ & $-18.57 \%$ & $22.68 \%$ & $-15.20 \%$ \\
\hline
\end{tabular}


Table 5. The HQMD competitiveness in the upper, middle, and lower reaches of HQMD in 2013-2018

\begin{tabular}{ccccccc}
\hline Year & $\begin{array}{c}\text { Lower } \\
\text { reaches }\end{array}$ & $\begin{array}{c}\text { Middle } \\
\text { reaches }\end{array}$ & $\begin{array}{c}\text { Upper } \\
\text { reaches }\end{array}$ & $\begin{array}{c}\text { Gap between lower } \\
\text { and middle reaches }\end{array}$ & $\begin{array}{c}\text { Gap between lower } \\
\text { and upper reaches }\end{array}$ & $\begin{array}{c}\text { Gap between middle } \\
\text { and upper reaches }\end{array}$ \\
\hline 2013 & 0.4387 & 0.2418 & 0.2298 & 0.1969 & 0.2089 & 0.0120 \\
2014 & 0.4467 & 0.2516 & 0.2368 & 0.1951 & 0.2099 & 0.0148 \\
2015 & 0.4504 & 0.2637 & 0.2389 & 0.1867 & 0.2115 & 0.0248 \\
2016 & 0.4641 & 0.2713 & 0.2511 & 0.1928 & 0.2130 & 0.0202 \\
2017 & 0.4761 & 0.2817 & 0.2584 & 0.1944 & 0.2177 & 0.0233 \\
2018 & 0.4945 & 0.2969 & 0.2665 & 0.1976 & 0.2280 & 0.0304 \\
Cumulative growth & $12.72 \%$ & $22.79 \%$ & $15.97 \%$ & 0.0036 & 0.0914 & 1.5333 \\
\hline
\end{tabular}

Table 6. The HQMD competitiveness in 11 YREB provinces in 2013-2018

\begin{tabular}{ccccccccc}
\hline Ranking & Province & $\mathbf{2 0 1 3}$ & $\mathbf{2 0 1 4}$ & $\mathbf{2 0 1 5}$ & $\mathbf{2 0 1 6}$ & $\mathbf{2 0 1 7}$ & $\mathbf{2 0 1 8}$ & Cumulative growth \\
\hline 1 & Shanghai & 0.5513 & 0.5570 & 0.5617 & 0.5834 & 0.5893 & 0.6100 & $10.65 \%$ \\
2 & Jiangsu & 0.4097 & 0.4192 & 0.4153 & 0.4245 & 0.4362 & 0.4545 & $10.93 \%$ \\
3 & Zhejiang & 0.3553 & 0.3638 & 0.3743 & 0.3844 & 0.4029 & 0.4189 & $17.90 \%$ \\
4 & Chongqing & 0.2947 & 0.3024 & 0.3172 & 0.3330 & 0.3478 & 0.3535 & $19.95 \%$ \\
5 & Anhui & 0.2403 & 0.2591 & 0.2693 & 0.2919 & 0.3160 & 0.3352 & $39.49 \%$ \\
6 & Hunan & 0.2487 & 0.2640 & 0.2728 & 0.2825 & 0.2955 & 0.3083 & $23.96 \%$ \\
7 & Hubei & 0.2626 & 0.2598 & 0.2643 & 0.2652 & 0.2775 & 0.2910 & $10.81 \%$ \\
8 & Sichuan & 0.2262 & 0.2337 & 0.2430 & 0.2587 & 0.2518 & 0.2554 & $12.91 \%$ \\
9 & Jiangxi & 0.2224 & 0.2236 & 0.2485 & 0.2454 & 0.2378 & 0.2532 & $13.85 \%$ \\
10 & Yunnan & 0.1920 & 0.1997 & 0.1970 & 0.2052 & 0.2322 & 0.2408 & $25.42 \%$ \\
11 & Guizhou & 0.2062 & 0.2114 & 0.1984 & 0.2074 & 0.2016 & 0.2164 & $4.95 \%$ \\
\hline
\end{tabular}

Table 7. The HQMD competitiveness of 30 Chinese provinces in 2018

\begin{tabular}{|c|c|c|c|c|c|c|c|c|}
\hline Provinces & HQMD Competitiveness & (A) & (B) & (C) & (D) & (E) & (F) & Categories \\
\hline Beijing & 0.6580 & 0.8305 & 0.6418 & 0.8303 & 0.3829 & 0.9838 & 0.4126 & \multirow{9}{*}{ High level } \\
\hline Shanghai & 0.6100 & 0.5358 & 0.6643 & 0.5027 & 0.5460 & 0.9049 & 0.9269 & \\
\hline Tianjin & 0.4899 & 0.4685 & 0.3793 & 0.5492 & 0.7054 & 0.9708 & 0.4099 & \\
\hline Guangdong & 0.4889 & 0.4088 & 0.3411 & 0.5511 & 0.6405 & 0.9286 & 0.5292 & \\
\hline Jiangsu & 0.4545 & 0.3814 & 0.3112 & 0.5417 & 0.6531 & 0.8733 & 0.4183 & \\
\hline Zhejiang & 0.4189 & 0.4133 & 0.3162 & 0.4625 & 0.6103 & 0.8544 & 0.3282 & \\
\hline Hainan & 0.3792 & 0.3020 & 0.3358 & 0.3924 & 0.2605 & 0.6364 & 0.5311 & \\
\hline Chongqing & 0.3535 & 0.3106 & 0.2651 & 0.4612 & 0.4615 & 0.9160 & 0.2251 & \\
\hline Anhui & 0.3352 & 0.4294 & 0.2471 & 0.3243 & 0.5401 & 0.8940 & 0.0939 & \\
\hline Shandong & 0.3109 & 0.2824 & 0.2607 & 0.3177 & 0.6724 & 0.8694 & 0.1679 & \multirow{15}{*}{ Medium level } \\
\hline Hunan & 0.3083 & 0.3019 & 0.3227 & 0.3454 & 0.5465 & 0.9173 & 0.0604 & \\
\hline Fujian & 0.3082 & 0.1917 & 0.3497 & 0.3206 & 0.5258 & 0.8737 & 0.2735 & \\
\hline Liaoning & 0.2991 & 0.2639 & 0.2432 & 0.2792 & 0.3615 & 0.7651 & 0.3579 & \\
\hline Shaanxi & 0.2939 & 0.2378 & 0.3373 & 0.3428 & 0.4751 & 0.9584 & 0.0950 & \\
\hline Hubei & 0.2910 & 0.2874 & 0.2762 & 0.3184 & 0.4024 & 0.9290 & 0.1823 & \\
\hline Sichuan & 0.2554 & 0.2220 & 0.2312 & 0.3432 & 0.2574 & 0.9012 & 0.0937 & \\
\hline Jiangxi & 0.2532 & 0.1394 & 0.2411 & 0.3611 & 0.3482 & 0.7046 & 0.1229 & \\
\hline Jilin & 0.2514 & 0.1835 & 0.2795 & 0.2618 & 0.4627 & 0.9480 & 0.1340 & \\
\hline Guangxi & 0.2512 & 0.1750 & 0.2794 & 0.2686 & 0.3903 & 0.9001 & 0.2069 & \\
\hline Hebei & 0.2462 & 0.1473 & 0.2911 & 0.2597 & 0.5028 & 0.8068 & 0.1258 & \\
\hline Henan & 0.2435 & 0.1426 & 0.2762 & 0.2694 & 0.5347 & 0.8004 & 0.0582 & \\
\hline Yunnan & 0.2408 & 0.1789 & 0.2717 & 0.3149 & 0.3342 & 0.6452 & 0.0563 & \\
\hline Ningxia & 0.2251 & 0.2161 & 0.1548 & 0.2924 & 0.3472 & 0.6308 & 0.0358 & \\
\hline Inner Mongolia & 0.2245 & 0.1341 & 0.3872 & 0.1946 & 0.2802 & 0.8703 & 0.1052 & \\
\hline Guizhou & 0.2164 & 0.1626 & 0.2533 & 0.2702 & 0.3368 & 0.8187 & 0.0145 & \multirow[t]{8}{*}{ Low level } \\
\hline Gansu & 0.2090 & 0.1367 & 0.1251 & 0.3006 & 0.3312 & 0.6765 & 0.0269 & \\
\hline Qinghai & 0.2066 & 0.1337 & 0.2736 & 0.2836 & 0.2428 & 0.5185 & 0.0106 & \\
\hline Heilongjiang & 0.1914 & 0.1721 & 0.1527 & 0.2093 & 0.2751 & 0.8418 & 0.1254 & \\
\hline Shanxi & 0.1849 & 0.1360 & 0.1345 & 0.2405 & 0.2995 & 0.6135 & 0.0783 & \\
\hline Xinjiang & 0.1694 & 0.1026 & 0.1825 & 0.1786 & 0.2546 & 0.6182 & 0.1539 & \\
\hline National average & 0.3123 & 0.2676 & 0.2942 & 0.3529 & 0.4327 & 0.8190 & 0.2120 & \\
\hline YREB average & 0.3397 & 0.3057 & 0.3091 & 0.3860 & 0.4579 & 0.8508 & 0.2293 & \\
\hline
\end{tabular}

Table 8. The national ranking of the 11 YREB provinces by HQMD competitiveness and its primary indices

\begin{tabular}{cccccccc}
\hline Province & Competitiveness & (A) & (B) & (C) & (D) & (E) & (F) \\
\hline Shanghai & 2 & 2 & 1 & 5 & 7 & 9 & 1 \\
Jiangsu & 5 & 7 & 11 & 4 & 3 & 14 & 4 \\
Zhejiang & 6 & 5 & 10 & 6 & 5 & 17 & 8 \\
Chongqing & 8 & 8 & 19 & 7 & 14 & 8 & 10 \\
\hline
\end{tabular}




\begin{tabular}{cccccccc}
\hline Anhui & 9 & 4 & 22 & 13 & 8 & 12 & 21 \\
Hunan & 11 & 10 & 9 & 10 & 6 & 7 & 24 \\
Hubei & 15 & 11 & 16 & 15 & 15 & 5 & 12 \\
Sichuan & 16 & 15 & 25 & 11 & 28 & 10 & 22 \\
Jiangxi & 17 & 25 & 24 & 9 & 19 & 23 & 18 \\
Yunnan & 22 & 19 & 18 & 17 & 22 & 25 & 26 \\
Guizhou & 25 & 22 & 21 & 22 & 21 & 19 & 29 \\
\hline
\end{tabular}

(2) In terms of space, the HQMD competitiveness was stronger in the east, with widening regional gaps; in terms of time, the HQMD competitiveness was improving across the board, especially in the central region.

Table 5 provides the HQMD competitiveness in the upper, middle, and lower reaches of the YREB in the sample period. In terms of space, the lower reaches had far stronger HQMD competitiveness than the middle and upper reaches; the middle reaches maintained a slight lead over the upper reaches. From 2013 to 2018, the gap of HQMD competitiveness between upper and lower reaches, and that between upper and middle reaches widened by 0.0914 and 1.5333 , respectively. To sum up, the HQMD competitiveness was stronger in the east, with widening regional gaps.

In terms of time, the HQMD competitiveness was improving in all three regions of the YREB throughout the sample period. The cumulative growths in the upper, middle and lower reaches were $15.97 \%, 22.79 \%$, and $12.72 \%$, respectively. The growth rate of the middle reaches was significantly higher than that of the upper and lower reaches, indicating that the central region is making the fastest progress in HQMD.

The main reasons for the above trends are as follows: The provinces in the lower reaches (e.g. Shanghai, Jiangsu, and Zhejiang) are traditional manufacturing powerhouses. But the manufacturing growth in this region is affected, as industrial upgrading and transfer are picking up speed. The provinces in the middle reaches (e.g. Hubei and Hunan) have the geographical advantage and industrial foundation to undertake the industrial transfer from the east. In recent years, these provinces have attracted many high-quality projects, enhancing their HQMD potential. The provinces in the upper reaches (e.g. Sichuan and Guizhou) have a weak manufacturing foundation, and a relatively low attractiveness to manufacturers, owing to the pressure of environmental protection. Hence, the regional gaps in HQMD competitiveness are still expanding.

(3) Five provinces maintain steady growth of HQMD competitiveness, and six provinces witnessed fluctuating growth. In the final manufacturing landscape, there were one leader, two subleaders, three supporters, and five followers.

Table 6 shows the HQMD competitiveness in the 11 YREB provinces in 2013-2018. In terms of provincial ranking, Shanghai, Jiangsu, Zhejiang, and Chongqing steadily occupied the top four spots; Anhui and Hubei switched their positions $\left(5^{\text {th }}\right.$ and $\left.7^{\text {th }}\right)$; Yunnan and Guizhou also swapped their places $\left(10^{\text {th }}\right.$ and $\left.11^{\text {th }}\right)$; the other three provinces remained unchanged in the ranking.

In terms of growth pattern, the HQMD competitiveness of all 11 provinces had improved significantly. The growth was steady in Shanghai, Zhejiang, Chongqing, Anhui, and Hunan, whose cumulative growths were $0.0587,0.0636,0.0588$, 0.0949 , and 0.0596 , respectively. These provinces ended up as the top five in the final ranking. The other six provinces went through fluctuating growth, and appeared on the lower half of the final ranking.

In terms of industrial landscape, the manufacturing industry in the YREB had one leader (Shanghai), two subleaders (Jiangsu and Zhejiang), and eight followers in 2013. During the sample period, this landscape was disrupted by the fast progress in Anhui, Hunan, and Chongqing. The HQMD competitiveness of the three provinces grew rapidly by $39.49 \%, 23.96 \%$ and $19.95 \%$, respectively. In 2018, Anhui, Hunan, and Chongqing developed into three important supporters of HQMD in the study area.

Through the sample period, Chongqing has forged two pillar industries, namely, automobile and electronic information, thanks to its important political status: municipality directly under the central government, national central city, and the first city to implement the China Western Development strategy. In recent years, Anhui has been actively integrating into the Yangtze River Delta urban agglomeration. With a favorable geographical location, Anhui is now the best destination of industrial transfer from the Yangtze River Delta. Meanwhile, Hunan has extended its industrial chain and expanded the industrial clusters around construction machinery and rail transit equipment, making the two industries competitive on the world stage.

By contrast, Hubei dropped by 2 places in the provincial ranking, owing to the sluggish development of its superior industries: the iron and steel industry was busy with structural transformation and upgrading to cut capacity; the market competitiveness of the automobile industry has declined amidst intense competition at home and abroad. Similar to Hubei, Guizhou also performed poorly in HQMD. There are two reasons for the underperformance: the traditional pillar industries like liquor, coal, electricity, and tobacco are hard to transform or innovate; tourism and big data are the development focus of Guizhou, rather than manufacturing.

(4) The YREB is the demonstration zone of China's HQMD, with $80 \%$ of its provinces falling in medium and high levels.

The HQMD competitiveness of 30 Chinese provinces (excluding Tibet, Hong Kong, Macao, and Taiwan) in 2018 were evaluated by the improved entropy TOPSIS model. Then, the authors identified the positions of the HQMD competitiveness of the 11 YREB provinces in China. Inspired by Wei and $\mathrm{Li}$ (2018), all 30 provinces were allocated to three categories (high level, medium level, and low level) by HQMD competitiveness, according to the formula of mean score $(\mathrm{M})$ and standard deviation $(\mathrm{SD})(\mathrm{M} \pm 0.5 \mathrm{SD})$. High level scores are greater than $0.3736(\mathrm{M}+0.5 \mathrm{SD})$; Medium level scores are greater than 0.2510 but smaller than 0.3736 (M+0.5SD M-0.5SD); Low level scores are smaller than 0.2510 (M-0.5SD). The HQMD competitiveness of 30 Chinese provinces in 2018 are displayed in Table 7. The national ranking of the 11 YREB provinces by HQMD competitiveness and its primary indices are exhibited in Table 8 .

As shown in Tables 7 and 8, three (27\%) YREB provinces belonged to the high level, six (55\%) to the medium level, and two (18\%) to the low level. The proportions (27\%: 55\%: 18\%) in the YREB are obviously better than those (23\%: 50\%: $27 \%$ ) across China. Overall, more than $80 \%$ of YREB provinces fell in high and medium levels. 
On average, the HQMD competitiveness in the YREB was 0.3397 , higher than the national average of 0.3123 . Besides, the average scores of the YREB in innovation, intensive utilization, structural upgrading, benefit optimization, environment coordination, and opening \& freedom were all higher than the national average scores.

Judging by primary indices, Shanghai, which had the second highest HQMD competitiveness in China, ranked first in intensive utilization, and opening \& freedom, and second in innovation. Therefore, Shanghai is the benchmark of HQMD in China. In addition, Jiangsu (4th in structural upgrading, and opening \& freedom), Zhejiang (5th in innovation, and benefit optimization), Hunan (6th in benefit optimization; 7th in environment coordination), and Hubei (5th in environment coordination) were in the forefront of the country in some of the primary indices. Therefore, the YREB is the demonstration zone of China's HQMD.

\section{CONCLUSIONS}

This paper firstly clarifies the connotation of HQMD, using the input-process-output model of the systems theory, and then constructs a scientific evaluation index system of HQMD competitiveness. After that, the entropy method was improved through the AHP, and combined with TOPSIS into an evaluation model of HQMD competitiveness. On this basis, the HQMD competitiveness of the YREB was empirically analyzed based on the panel data from 2013 to 2018 . The main conclusions are drawn as follows:

(1) The overall HQMD competitiveness improved steadily, under the strong boost from two factors and slight constraint from two factors.

(2) In terms of space, the HQMD competitiveness was stronger in the east, with widening regional gaps; in terms of time, the HQMD competitiveness was improving across the board, especially in the central region.

(3) Five provinces maintain steady growth of HQMD competitiveness, and six provinces witnessed fluctuating growth. In the final manufacturing landscape, there were one leader, two subleaders, three supporters, and five followers.

(4) The YREB is the demonstration zone of China's HQMD, with $80 \%$ of its provinces falling in medium and high levels.

The HQD is a comprehensive, coordinated, and sustainable development model. Considering the main problems with the HQMD in the YREB, this paper presents the following policy recommendations:

(1) Make up for the weak links and enhance the overall HQMD competitiveness.

Benefit optimization and opening \& freedom are the two weak links that restrict the HQMD competitiveness in the YREB. To improve benefit optimization, China should tone down the expansion of real estate and finance in the transform from real economy to fictitious economy, highlight the importance of real economy to national economy, and encourage the financial industry to divert more funds to manufacturing, such that manufacturing could contribute greater to economic growth and social progress.

To improve opening $\&$ freedom, China should speed up the supply-side reform of manufacturing, promote the structural reform towards intelligent manufacturing, and strengthen the competitive advantage of manufactured products in the global market. In the meantime, the domestic consumption pattern should be upgraded to unleash the potential of domestic consumption, and to offset the adverse impact from the grim prospect of the global market.

(2) Promote regional linkages and enhance regional coordination in HQMD.

In the YREB, the regional gaps in HQMD competitiveness are still expanding, that is, the imbalance of regional development is increasingly severe. To curb the imbalance, the upper reaches of the YREB should step up the implementation of China Western Development strategy, relying on their resource endowment and policy advantages. According to the principles of regional linkage and dislocation competition, this region should undertake some national manufacturing projects, accept project transfer from eastern and central regions, and introduce local incubation programs. Moreover, this region should promote the free circulation of innovative elements, and fully integrate into the industrial chain of manufacturing.

(3) Strengthen characteristic industries and upgrade the manufacturing structure.

Among the 11 YREB provinces, Chongqing, Anhui, and Hunan are the top three in the middle level, while Yunnan and Guizhou are in the top half in the low level. These provinces face the demand and have the capability to upgrade the manufacturing structure. Since the HQMD hinges on pillar industries, the five provinces should strengthen their characteristic industries (e.g. automobile manufacturing, electronic information, household appliances, equipment manufacturing, new materials, and biological medicine) by extending the industrial chain, expanding the industrial cluster, and digging into core technologies. In this way, these provinces could create industrial brands with national and global influence, and quickly improve their HQMD competitiveness.

\section{ACKNOWLEDGEMENT}

The authors acknowledge the financial support from the Philosophy and Social Sciences Foundation of Shenzhen (Grant No.: SZ2020C006).

\section{REFERENCES}

[1] Sohal, A. (2014). Innovative manufacturing: An Australasian perspective. International Journal of Production Research, 52(21): 6414-6415. https://doi.org/10.1080/00207543.2014.969908

[2] Cruz-Cázares, C., Bayona-Sáez, C., García-Marco, T. (2013). You can't manage right what you can't measure well: Technological innovation efficiency. Research Policy, 42(6-7): 1239-1250. https://doi.org/10.1016/j.respol.2013.03.012

[3] Grupp, H., Schubert, T. (2010). Review and new evidence on composite innovation indicators for evaluating national performance. Research Policy, 39(1): 67-78. https://doi.org/10.1016/j.respol.2009.10.002

[4] Zeng, S.L., Liu, Y.Q., Ding, J.J., Xu, D.L. (2020). An empirical analysis of energy consumption, FDI and high quality development based on time series data of Zhejiang province. International Journal of Environmental Research and Public Health, 17(9): 3321. https://doi.org/10.3390/ijerph17093321

[5] Sedgley, H.N., Tank, M. (2015). The roles of innovators and labor in a Schumpeterian factor endowments based 
model of intra-industry trade. Review of International Economics, 23(5): 873-896. https://doi.org/10.1111/roie.12196

[6] Gryshova, I., Kyzym, M., Khaustova, V., Korneev, V., Kramarev, H. (2020). Assessment of the industrial structure and its influence on sustainable economic development and quality of life of the population of different world countries. International Journal of $\begin{array}{lll}\text { Production } & \text { Economics, } & \text { 12(5): } 2072 .\end{array}$ https://doi.org/10.3390/su12052072

[7] Li, T.X., Li, Y., An, D.F., Han, Y.W., Xu, S.Y., Lu, Z.M., John, C. (2019). Mining of the association rules between industrialization level and air quality to inform highquality development in China. Journal of Environmental Management, 246: 564-574 https://doi.org/10.1016/j.jenvman.2019.06.022

[8] Nallusamy, S., Ganesan, M., Balakannan, K. (2015). Environmental sustainability evaluation for an automobile manufacturing industry using multi-grade fuzzy approach. International Journal of Engineering Research in Africa, 19: 123-129. https://doi.org/10.4028/www.scientific.net/JERA.19.12 3

[9] Bhatt, Y., Ghuman, K., Dhir, A. (2020). Sustainable manufacturing. Bibliometrics and content analysis. Journal of Cleaner Production, 260(19): 120988. https://doi.org/10.1016/j.jclepro.2020.120988

[10] Ellerbrock, M.J. (2018). Sustainable development requires environmental justice. International Journal of Sustainable Development and Planning, 13(2): 208-214. https://doi.org/10.2495/SDP-V13-N2-208-214

[11] Han, S.F., Liu, H.Y., Lin, Y. (2020). Measurement of the innovation efficiency of the hi-tech industry in China and its influencing factors. International Journal of Sustainable Development and Planning, 15(3): 277-286. https://doi.org/10.18280/ijsdp.150303

[12] Yu, X., Yan, J.D., Zhang, F., Hamma, M., Zhang, Q. (2020). Sustainable development of sci-tech service intermediaries based on triple helix model of innovation. International Journal of Sustainable Development and Planning, 15(4): 513-519. https://doi.org/10.18280/ijsdp.150411

[13] Wang, S.H., Lu, X.L. (2020). Design and application of an evaluation index system for urban development quality of China's sub-provincial cities in the new era. International Journal of Sustainable Development and Planning, 15(3): 327-334. https://doi.org/10.18280/ijsdp.150309
[14] Hallak, J.C., Sivadasan, J. (2013). Product and process productivity: Implications for quality choice and conditional exporter premia. Journal of International Economics, 91(1): 53-67. https://doi.org/10.1016/j.jinteco.2013.05.001

[15] Zhang, J.K., Hou, Y.Z., Liu, P.L., He, J.W., Zhuo, X. (2019). Goal Requirements and Strategic Path of HighQuality Development. Management World, (7): 1-7.

[16] Jabbour, A.B.L.D., Ndubisi, N.O., Seles, B.M.R.P. (2020). Sustainable development in Asian manufacturing SMEs: Progress and directions. International Journal of Production Economics, 225(7): 107567. https://doi.org/10.1016/j.ijpe.2019.107567

[17] Zheng, J., Chen, A.K., Zheng, W., Zhou, X.J., Bai, B., Wu, J., Ling, W., Ma, H.P., Wang, W. (2020). Effectiveness analysis of resources consumption, environmental impact and production efficiency in traditional manufacturing using new technologies: Case from sand casting. Energy Conversion and Management, 209(7):

112671. https://doi.org/10.1016/j.enconman.2020.112671

[18] Jiang, H., Hua, M., Zhang, J., Cheng, P., Ye, Z., Huang, M., Jin, Q. (2020). Sustainability efficiency assessment of wastewater treatment plants in China: A data envelopment analysis based on cluster benchmarking. Journal of Cleaner Production, 244: 118729. https://doi.org/10.1016/j.jclepro.2019.118729

[19] Shi, T., Zhang, W., Zhou, Q., Wang, K. (2020). Industrial structure, urban governance and haze pollution: Spatiotemporal evidence from China. The Science of the Total Environment, 742: 139228. https://doi.org/10.1016/j.scitotenv.2020.139228

[20] Ma, G.X., Wang, J.N., Yu, F., Yang, W.S., Ning, J., Peng, F., Zhou, X.F., Zhou, Y., Cao, D. (2020). Framework construction and application of China's Gross EconomicEcological Product accounting. Journal of Environmental Management, 264(12): 109852. https://doi.org/10.1016/j.jenvman.2019.109852

[21] Zhang, Y.L., Sun, J., Yang, Z.J., Wang, Y. (2020). Critical success factors of green innovation: Technology, organization and environment readiness. Journal of Cleaner Production, 264(23): 121701. https://doi.org/10.1016/j.jclepro.2020.121701

[22] Zhang, T. (2020). Theoretical interpretation and measurement methods of high-quality development in China. the Journal of Quantitative \& Technical Economics, 37(5): 23-43. 